\title{
Regionality Revisited: An Examination of the Direction of Spread of Currency Crises
}

\author{
Amil Dasgupta Roberto Leon-Gonzalez Anja Shortland \\ This draft: June 2006 \\ Revised for the Journal of International Money and Finance
}

\begin{abstract}
What determines the direction of spread of currency crises? We examine data on waves of currency crises in 1992, 1994, 1997, and 1998 to evaluate several hypotheses on the determinants of contagion. We simultaneously consider trade competition, financial links, and institutional similarity to the "ground-zero" country as potential drivers of contagion. To overcome data limitations and account for model uncertainty, we utilize Bayesian methodologies hitherto unused in the empirical literature on contagion. In particular, we use the Bayesian averaging of binary models which allows us to take into account the uncertainty regarding the appropriate set of regressors.

We find that institutional similarity to the ground-zero country, as measured by qualityof-governance indicators, plays an important role in determining the direction of contagion in all the emerging market currency crises in our dataset. We thus provide persuasive evidence in favor of the "wake up call" hypothesis for financial contagion. Trade and financial links may also play a role in determining the direction of contagion, but their importance varies amongst the crisis periods and may be sensitive to the specification of the prior.
\end{abstract}

JEL Classification: F31, F32, C11

Keywords: Financial contagion; Currency crises; Governance; Bayesian Model Averaging

Addresses for correspondence: Dasgupta (corresponding author) Department of Accounting and Finance, London School of Economics, London, WC2A 2AE, UK. E-mail: a.dasgupta@1se.ac.uk Leon-Gonzalez and Shortland: Department of Economics, University of Leicester, Leicester, LE1 7RH, UK

Acknowledgements: We thank the editor, James Lothian, and two anonymous referees for valuable comments that have shaped this revision. We are grateful to Hugo Benitez-Silva, Giancarlo Corsetti, Emilio Gómez-Déniz, Fernando Fernández-Rodríguez, Andrew Patton, Jorge Pérez-Rodríguez, John Rust, and Francisco J. Vázquez-Polo for helpful comments, and to Beatrice Weder for sharing the data on the 1998 crisis. Dasgupta thanks the ESRC for financial support via grant RES-156-25-0026. 


\section{Introduction}

Currency crises tend to occur in waves. In repeated instances from the early 1970s to the late 1990s it has been observed that when speculative attacks lead to a currency crisis in one country, market volatility tends to spread to other countries in the region and elsewhere. Several mechanisms have been proposed to explain this phenomenon, generally referred to as contagion. Commonly discussed mechanisms include the transmission of crises through trade and financial links between countries, as well as the (rational) updating of beliefs by financial traders about the sustainability of specific institutional and developmental models. The latter is sometimes referred to as the "wakeup call" theory of financial contagion.

In this paper we empirically evaluate the relative importance of a number of potential transmission mechanisms that have been proposed in the existing literature, by analysing four waves of currency crises in the 1990s. We make two contributions.

First, we simultaneously include institutional (quality-of-governance) variables alongside the trade, finance and macroeconomic variables commonly analysed in empirical literature on contagious currency crises, thereby directly testing the "wake-up call" hypothesis.

Second, we utilize Bayesian methodologies hitherto unused in the empirical literature on contagion to overcome model uncertainty and data limitations. In particular, we use Bayesian averaging of binary models, which allows us to take into account the uncertainty regarding the set of regressors that should be included in the empirical analysis of contagion.

Before proceeding further, it is worth clarifying the remit of our exercise. In this paper we do not seek to enter the debate on whether contagion exists. While there are now several theoretical equilibrium models of contagion, there is not yet complete empirical agreement about whether contagion exists. ${ }^{1}$ In this paper, we simply assume that contagion exists and aim only to shed light on the mechanisms by which it may propagate.

\footnotetext{
${ }^{1}$ See Dungey and Tambakis (2003) for a discussion of the term "contagion" as well as Dungey et al (2003) for a detailed review of the contagion literature.
} 
Much of the extant empirical literature on contagious currency crises stresses the phenomenon of regional contagion. It focuses on trade and financial links, which tend to occur in geographical clusters, and finds evidence in favor of both as potential transmission mechanisms for contagion. ${ }^{2}$ However, the currency crises of the 1990s have spread far beyond the region of the original crisis country. Glick and Rose (1999) deem that Hong Kong, Indonesia, the Philippines and Thailand were affected by the "Mexican crisis" in 1994/1995, while Argentina, Brazil, the Czech Republic, Hungary and South Africa are considered to have been among the victims of the Asian Crisis. According to Van Rijckeghem and Weder (2001) the Russian crisis of 1998 affected 16 countries outside the former Soviet Union, including Argentina, Hong Kong, Indonesia, South Africa and Turkey. While trade competition in third markets or financial links may be possible explanations for extra-regional contagion, it is also interesting to examine the possibility that a speculative attack on a country follows from a "wake-up call" regarding a specific model of development: a currency crisis in one country may highlight vulnerabilities associated with a particular set of institutional features, which may also be found in other countries outside the region.

There is now much data measuring the institutional features of different countries. Our paper contributes to the literature by directly testing the extent to which institutional similarity with the "ground zero" country determines the direction of spread of currency crises. This is done while simultaneously considering standard factors such as trade competition and financial links to give an overall view of the drivers of financial contagion in foreign exchange markets.

In addition, our paper utilizes recent econometric methodology that is relevant to the empirical analysis of financial contagion. There is no universally agreed-upon theoretical model of contagion: several alternative hypotheses coexist. In the presence of such model uncertainty, Bayesian model averaging (BMA) is a natural candidate for empirical work in this area. The idea of BMA was first proposed by Leamer (1978). It is a tool for forecasting and estimation when the researcher does not know the true model. Starting from a prior where all possible models are considered to be equally good, the

\footnotetext{
${ }^{2}$ Eichengreen et al (1996), Glick and Rose (1999), Kaminsky and Reinhart (2000), Caramazza et al (2000), Van Rijckeghem and Weder (2003).
} 
method allows researchers to estimate the posterior probabilities of the models, using the data, and then weight their estimates and forecasts from each model by such posterior probabilities. While BMA has recently been extensively used in applied problems (see various references below), we are the first to use it in the context of financial contagion.

In addition to this, Bayesian methods allow us to overcome data limitations. Empirical samples in the contagion literature are of necessity small: in all previous studies the number of observations is below 100 countries. Of these only a small subset experience a crisis in each episode of contagion. Unlike maximum likelihood, Bayesian methods are also valid in small samples.

\section{Summary of Results}

We examine data on currency crises in 1992, 1994, 1997, and 1998, focussing on the relative importance of trade, financial links, and institutional similarity on the direction of contagion. We report the following results:

1. Institutional (quality-of-governance) variables play a vital role in the spread of all emerging market currency crises in our dataset. Following a crisis in the "ground zero" country, countries that are, ceteris paribus, institutionally similar have a higher probability of experiencing a currency crisis. In the crises of 1994, 1997, and 1998, the increase in crisis probabilities due to institutional similarity ranges between $24 \%$ and $63 \%$. Our results, therefore, provide substantial empirical support for the "wake-up call" hypothesis for financial contagion.

In contrast, however, institutional similarity has less explanatory power in the 1992 EMU crisis, confirming the intuition that the "wake-up call" hypothesis is most relevant for emerging markets.

2. Other factors, such as financial links (through common lenders) and trade also play a role in determining the direction of contagion, but their importance may vary across crisis periods. For example, financial links appear to be important in the 1998 crisis, while trade competition is important for 1997. The relevance of these variables is also sensitive to the specification of the prior. 
Our paper is linked to a large and growing literature on financial contagion. In what follows, we briefly survey this literature.

\section{Literature review}

The literature has considered a number of potential channels for international financial contagion. ${ }^{3}$ The first potential channel derives from international trade. ${ }^{4}$ If a country experiences a sharp devaluation it gains a competitive advantage over its trade partners and over competitors in third markets. To the extent that (the expectation of) deteriorating current account deficits signals potential currency weakness, countries with strong trade connections to the "ground zero country" become more likely to experience a speculative attack. Glick and Rose (1999) examine the importance of the trade channel and find statistical evidence from cross-country data that currency crises spread among countries which have strong trade links.

A second potential channel of contagion derives from financial linkages between countries. ${ }^{5}$ Here contagion arises because groups of countries rely on common creditors and investors. If a country experiences a speculative attack, its major creditor banks may experience liquidity problems, which undermine their ability to provide emergency finance to other countries or trigger capital outflows to restore capital adequacy ratios. Therefore, countries which rely on external funding from the same creditors and investors as the "ground zero country" become vulnerable to speculative attacks. The importance of the "common creditor effect", meaning contagion through bank lending, has been empirically examined by Van Rijckeghem and Weder (2001 and 2003), Caramazza et al. (1999), Hernandez and Valdes (2001) and Kaminsky and Reinhart (2000). The results indicate that vulnerability to speculative attacks can spread among clusters of countries which depend on the same lenders. Caramazza et al. (1999) additionally show that countries which are more important to the common lenders are more likely to become crises countries than those which only receive a very small proportion of the common lenders' total lending.

\footnotetext{
${ }^{3}$ See Pericoli and Sbracia (2001) and Dungey et al (2003) for literature reviews. Chui et al (2004) sets out the framework for assessing external vulnerabilities in more detail.

${ }^{4}$ For a theoretical formalization of this idea see, for example, Gerlach and Smets (1995).

${ }^{5}$ For theoretical models formalizing this hypothesis, see, for example, Goldstein and Pauzner (2005), Allen and Gale (2000), and Dasgupta (2004).
} 
A third channel for contagion derives from shared updating by market participants about the sustainability of specific institutional frameworks or development models. Such a view of contagion is commonly referred to as the "wake-up call" hypothesis. ${ }^{6}$ The argument here is that if a country with a particular development strategy, institutional setup or macroeconomic situation experiences a devaluation, this may be seen as revealing information about the vulnerability of countries of a similar "type" and hence cause the spread of crises. ${ }^{7}$ A good example of a major re-evaluation of an economic development strategy was seen in the rapid turn-around in 1997 from applauding the "Asian Miracle"8 to deploring the "Asian Debacle". Months before the crisis South East Asia's "dedicated capitalism" and "Asian values" were praised and held up as strategies for successful development the world over, but were swiftly condemned as "crony capitalism" in the immediate aftermath of the crisis and held responsible for economic vulnerabilities. Issues such as "corruption", "regulatory quality" and "transparency" suddenly came to the forefront of investor attention and may have contributed to the spreading of the crisis to countries perceived to have similar deficits in accountability and data quality. While a large literature has emerged in recent years to measure and quantify the effects of legal and institutional variables on financial development ${ }^{10}$ and financial fragility ${ }^{11}$ to our knowledge no direct test of the impact of institutional similarity on financial contagion has been carried out. It is a contribution of this paper to provide a direct examination of the "wake-up call" hypothesis using measures of institutional similarity provided in the literature.

\footnotetext{
${ }^{6}$ The term "wake-up call" originates from Goldstein (1998). For theoretical formalizations of this hypothesis, see Rigobon (1998) and Basu (1998). Van Rijckeghem and Weder (2003) provide evidence for the "wake-up call" hypothesis from the Russian crisis, which caused generalized outflows from emerging markets.

${ }^{7}$ See Drazen (1998) on "information externalities"

${ }^{8}$ See for example the 1993 World Bank publication "The South East Asian Miracle" hailing the "fundamentally sound development policies" and "tailored government interventions" in eight high performing Asian economies.

${ }^{9}$ Porter (1996)

${ }^{10}$ See Beck and Levine (2003) for a review

${ }^{11}$ Demirgüç-Kunt and Detragiache. (1998), Kaminsky and Reinhart (1999), Kaminsky and Schmukler (2003)
} 


\section{Data}

In Table 1 we summarize the variables that we use. For a given wave of currency crises and for each country $i$, the dependent (binary) variable records whether country $i$ experienced a currency crisis following the crisis in the ground zero country. ${ }^{12}$ It is taken from Glick and Rose (1999) for 1992, 1994 and 1997 and from Van Rijckeghem and Weder (2001) for 1998.

To quantify the trade channel for contagion we use the "trade share" indicator computed by Glick and Rose (1999) for 1992, 1994 and 1997 and Van Rijckeghem and Weder (2001) for 1998. A high value of this index indicates that the country's exports compete intensely with the ground zero country in third markets.

To measure financial links between countries, we choose two indicators of competition for funds based on Caramazza et al. (1999). Define the "common lender" to be the creditor country most exposed to the ground zero country. For any given country, our first indicator indexes the importance of the common lender to that country. For the emerging market crises the "common lenders" are the US (1994), Japan (1997) and Germany (1998). For example, in the Russian crisis of 1998 the indicator looks at the proportion of country i's total borrowing which derived from German banks. Our second indicator measures how important a potential target country is to the common lender. Thus, the indicator measures country i's borrowing as a proportion of the total loans made by the common lender. We also include a multiplicative interaction of these two indicators. The data are taken from the Bank for International Settlements' (BIS) consolidated data, covering bank lending from banking systems in the "reporting area" of 18 industrialised countries to countries outside the "reporting area". ${ }^{13}$ All indicators refer to banks' position reported at the date closest to the respective crises i.e. December 1994 for the Mexican crisis, June 1997 for the Asian crisis and June 1998 for the Russian crisis. The BIS data only cover lending from the reporting area to countries outside the reporting area, meaning that no financial data are available for the 1992 crisis in the

\footnotetext{
${ }^{12}$ Glick and Rose use journalistic and academic histories of crises episodes to identify countries suffering from contagion, Van Rijckeghem and Weder (2001) utilise a panel of IMF experts.

${ }^{13}$ The reporting area countries are: Austria, Belgium, Canada, Denmark, Finland, France, Germany, Ireland, Italy, Japan, Luxembourg, Netherlands, Norway, Spain, Sweden, Switzerland, UK and the US.
} 
European exchange rate mechanism. However, it is likely that contagion through financial centres is a phenomenon limited to emerging market currency crises.

Our analysis of the "wake-up call" hypothesis is based on a number of variables that have been used in the literature to capture institutional similarity between countries. To measure institutional similarity, we use a number of variables taken from the set of governance indicators compiled by Kaufman et al. (1999) for the World Bank. In particular, we test whether variables such as corruption, regulatory quality, and the degree to which the rule of law is upheld influence whether investors withdraw capital from a country. A disadvantage of this dataset is that data collection only began in 1996. However, Kaufmann et al. (2005) note that the quality of governance tends to be highly persistent, because institutions change only slowly. ${ }^{14}$ Changes in governance over time are small relative to the level of the governance indicators and the reported error margin on the estimates. Changes in annual governance estimates where the $90 \%$ confidence intervals do not overlap are only reported in a tiny minority of countries. ${ }^{15} \mathrm{We}$ therefore take the average score of each country in the years 1996, 1998 and 2000 and used this for each episode of the 1990s currency crises. For each country, and for each relevant variable, we then compute a measure of similarity to the ground zero country. For example, let $c_{i}$ be the corruption index for country $i$ that is constructed as just described, and let $c_{0}$ be the same variable measured for the ground zero country. Then the variable that we use in our analysis is defined as: $\left|c_{i}-c_{0}\right| /\left|c_{o}\right|$. An analogous index of similarity is constructed for the other two institutional variables.

An additional way of capturing institutional similarity derives from legal origin. The large literature on law and finance (e.g. La Porta et al. 1998) argues that a country's legal system (mostly acquired through colonisation or occupation) has important effects on how confidently investors transact in a country, and that this differs significantly between Anglo-Saxon common law and French, German and Scandinavian civil law systems. ${ }^{16}$ Motivated by this literature, we complement our core measures of institutional similarity summarized above by an indicator of common legal origin, which takes the

\footnotetext{
${ }^{14} \mathrm{http}: / /$ www.worldbank.org/wbi/governance/pdf/GovMatters_IV_main.pdf

${ }_{16}^{15} \mathrm{http}: / /$ www.worldbank.org/wbi/governance/pdf/govmatters3_wber.pdf

${ }^{16}$ See Beck et al (2001) for a review
} 
value 1 if a country has the same legal system as the ground zero country. The data are taken from La Porta et al. (1998).

We include relative geographical distance to the ground zero country as a "control variable" in our regressions. Relative distance is relevant as a control for at least two reasons. First, trade competition and financial links tend to be regionally clustered, and thus it is worth considering these effects after controlling for pure geographic regionality. Second, countries that are closer are likely to have more similar institutions and culture. Thus, relative distances may also capture institutional similarity not captured by the more direct measures above. The distances between countries were computed as the distances between capital cities, using the distance calculator provided by Darrell Kindred $^{17}$ at http://www.indo.com/distance.

Finally, we use a number of macro-economic variables as additional control variables, such as current account and budget deficits, countries' reserve positions, credit expansion, inflation and growth performance. These variables control for the possibility that a country would have fallen into crisis regardless of the attack on the first country, because of its own weak macroeconomic fundamentals. ${ }^{18}$ In our choice of control variables, we have been guided by the prior work of Eichengreen et al. (1996), Glick and Rose (1999) and Van Rijckeghem and Weder (2003). The variables are computed or taken from the IFS for the period preceding the crisis ${ }^{19}$. This reflects both the delay in data becoming available and the fact that in the immediate aftermath of a currency crisis there is usually a significant worsening of the macroeconomic situation.

\section{Methodology}

\subsection{Bayesian Model Averaging}

Let $Z$ be the $n \times k$ matrix that contains all variables that could potentially enter in the regression equation, where $n$ is the number of observations and $k$ is the number of potential regressors. Let $Y=\left(y_{1}, \ldots, y_{n}\right)^{\prime}$ be an $n x 1$ vector of observed binary variables.

\footnotetext{
${ }^{17}$ This calculator uses the latitudes and longitudes of the cities concerned and then computes the distance between them by using the Geod program, which is part of the PROJ system, a set of cartographic projection tools, provided by the US Geological Survey at ftp://kai.er.usgs.gov/pub/.

${ }_{18}$ See e.g. Kaminsky et al (1998) for a review of the empirical currency crises literature

191994 for Mexico, 1996 for Asia and 1997 for Russia
} 
We consider all binary probit models that result from including a different subset of $Z$ as explanatory variables. This gives rise to $2^{k}$ models. In particular, model $M_{j}$ is defined as the following probit model:

$$
Y^{*} \mid \theta \sim N\left(Z_{j}^{\prime} \theta_{j}, I_{n}\right), \quad y_{i}=\left\{\begin{array}{lll}
1 & \text { if } & y_{i}^{*} \geq 0 \\
0 & \text { if } & y_{i}^{*}<0
\end{array}\right.
$$

where $Y^{*}=\left(y_{1}^{*}, \ldots, y_{n}^{*}\right)^{\prime}$ is an $n x 1$ vector containing unobserved latent data, $Z_{j}$ is a $n \times k_{j}$ submatrix of $Z, \theta$ is a $k \times 1$ vector of unknown parameters, $\theta_{j}$ is a $k_{j} \times 1$ subvector of $\theta$ containing the elements of $\theta$ that are included (i.e., not restricted to be zero) in model $M_{j}$, and $I_{n}$ is the identity matrix of dimension $n$.

Our inference for $\theta$ is based on the posterior mean and credible regions ${ }^{20}$ of the posterior density of $\theta(\pi(\theta \mid Y, Z))$, which is a weighted average of the posterior densities obtained under each of the models $\left(\pi\left(\theta \mid Y, Z, M_{j}\right)\right)$ :

$$
\pi(\theta \mid Y, Z)=\sum_{j=1}^{2^{k}} \pi\left(M_{j} \mid Y, Z\right) \quad \pi\left(\theta \mid Y, Z, M_{j}\right)
$$

Here, $\pi\left(M_{j} \mid Y, Z\right)$ represents the posterior probability of model $M_{j}$, which is given by Bayes' Rule as follows:

$$
\pi\left(M_{j} \mid Y, Z\right)=\frac{\pi\left(M_{j}\right) \pi\left(Y \mid Z, M_{j}\right)}{\sum_{l=1}^{2^{k}} \pi\left(M_{l}\right) \pi\left(Y \mid Z, M_{l}\right)} \text { with } \pi\left(Y \mid Z, M_{j}\right)=\int \pi\left(Y \mid \theta, Z, M_{j}\right) \pi\left(\theta \mid M_{j}\right) d \theta
$$

where $\pi\left(M_{j}\right)$ is the prior probability of model $j, \pi\left(\theta \mid M_{j}\right)$ is the prior density of $\theta$ under model $M_{j}$, and $\pi\left(Y \mid \theta, Z, M_{j}\right)$ is the likelihood.

We now define a crucial concept. The probability of inclusion for a (possibly singleton) set of explanatory variables $S_{j}$ is the joint posterior probability of all models that include at least one of the variables in $S_{j}$. In other words, the probability of inclusion of $S_{j}$ is the probability that at least one variable in $S_{j}$ has a non-zero effect on the expected outcome of the dependent variable. Thus, a zero inclusion probability implies that all of the coefficients in $\theta$ that correspond to $S_{j}$ are equal to zero. Inclusions probabilities will

\footnotetext{
${ }^{20}$ A $95 \%$ credible interval is the Bayesian analogue of a frequentist $95 \%$ confidence interval, and it is an interval that contains the true value of the parameter with probability $95 \%$ (e.g. see Koop 2003, p. 44).
} 
be crucial to interpreting our results: variables with high posterior inclusion probabilities are relevant determinants of contagion; others are not.

Our Bayesian methodology presents two important advantages over its more commonly used classical counterparts in the context of the contagion literature. First, as we have already noted, it allows us to control for model uncertainty. Second, Bayesian methods are valid in small samples. Both of these properties make Bayesian methods particularly suitable for the empirical analysis of financial contagion.

\subsection{Prior}

We use a prior that is computationally convenient and relatively uninformative. For each model $M_{j}$, we choose a normal prior as follows:

$$
\theta_{j} \mid M_{j} \sim N(0, V), \quad V_{j}=g\left(Z_{j}^{\prime} Z_{j}\right)^{-1}, g>0
$$

This class of priors has been extensively used for Bayesian estimation (e.g. Zellner, 1986,

Poirier 1985, Fernandez Ley and Steel, 2001). A prior mean of zero implies that we consider outcomes $y_{i}=1$ and $y_{i}=0$ to be equally likely a priori for $i=1, \ldots, n$. It also implies that a priori each covariate is equally likely to have a positive or a negative effect. The prior variance-covariance matrix depends on the scalar parameter $g$. It is instructive to think of our choice of $g$ in terms of the implied distribution of the following quantity:

$$
\bar{\pi}=\operatorname{Pr}\left(y=1 \mid \bar{z}_{j}, \theta_{j}, M_{j}\right),
$$

i.e, the ex ante probability, under model $M_{j}$, that the average country (a country with average values of regressors) experiences a currency crisis.

While it may be tempting to make our prior "more uninformative" by choosing a very large value of $g$, it is easy to see that this does not necessarily result in a reasonable prior. Very large values of $g$ imply that, a priori, we expect $\bar{\pi}$ to be either 1 or 0 and consequently marginal effects (on probabilities) to be approximately zero. ${ }^{21}$ Therefore, instead of arbitrarily fixing a very large value for $g$, we carefully adapt priors that have been proposed in the existing literature for other related models. In particular, we use three values for $g$. Details of the prior-elicitation process for $g$ are provided in Appendix A. We summarize our choices here.

\footnotetext{
${ }^{21} \mathrm{We}$ comment further on this issue in Appendix A.
} 
Our first choice for $g$ is given by:

$$
g=\bar{g}=\left(\bar{z}_{j}^{\prime}\left(Z_{j}^{\prime} Z_{j}\right)^{-1} \bar{z}_{j}\right)^{-1}
$$

This choice is tantamount to assuming that the prior distribution of $\bar{\pi}$ is uniform, a choice recommended by Geisser (1984) for the estimation of a probability.

Our second choice of $g$ is given by

$$
g=2.46 \bar{g}
$$

This amounts to assuming that the a priori distribution of $\bar{\pi}$ is approximately $\operatorname{Beta}(1 / 2,1 / 2)$, a prior recommended in the literature for the estimation of probabilities (Lee 1987). Compared to the uniform prior, the Beta prior gives slightly more weight to values of $\bar{\pi}$ near to 0 and 1 . Finally, for sensitivity analysis we also consider $g=5 \bar{g}$.

We carry out our computations for all three values of $g$.

\subsection{Computation}

For our computations, we use the algorithm of Holmes and Held (2006) who extend the methodology of Albert and Chib (1993) to allow for model uncertainty. The Holmes and Held algorithm is a Markov Chain that visits a model $\left(M_{n}\right)$ at each iteration $n$, and also generates a value for $\theta$ conditioning on $M_{n}$ and the data. A priori all models are given equal probability. Starting with any arbitrary initial model and starting value of $\theta$, Holmes and Held (2006) show that, as the number of iterations increases, the models and parameter values generated can be regarded as a sample from the true posterior distribution of models and parameters. Therefore, posterior means and other quantities of interest can be easily approximated with their sample analogues. The posterior probability of model $M_{j}$ is given by the proportion of iterations that visit model $M_{j}$. We provide details of the algorithm in Appendix A.

The results below derive from 165,000 iterations of the algorithm. The first 5,000 iterations are discarded. Essentially identical results were obtained with an independent run of fewer $(65,000)$ iterations, indicating good convergence. 


\section{Results}

Our main economic results are presented in Tables 2 and 3 . Tables 4 and 5 assess the outof-sample predictive power of the models. The dependent variable is binary, taking value one if the country concerned suffered a crisis. For each independent variable we report three quantities. First, we report the probability of inclusion of the variable $(p)$, as defined in Section 4.1. This is the probability that the effect associated with a regressor is different from zero. Second, since Probit coefficients are hard to interpret, we report the posterior mean for the marginal effect of each variable. These marginal effects are evaluated at the sample mean of variables. ${ }^{22}$ Third, for each marginal effect, we include the $95 \%$ credible interval, as defined in Section 4.1. This is the Bayesian analogue to the classical 95\% confidence interval in a Maximum Likelihood estimation. Finally, at the bottom of each table, we report the joint inclusion probability for the institutional similarity variables (R. Law, Reg. Q. and Corrupt) and for the finance variables (Fi1, Fi2 and $F i 1^{*} F i 2$ ). Since our goal is to understand whether trade competition, financial links, or institutional similarity drive financial contagion, it is important for us to compare the joint probabilities of inclusion of these different categories of variables. The results reported in Tables 2 and 3 correspond to the prior with $g=\bar{g} 2.46$. The results that we comment upon are robust to the 3 choices of $g$, unless otherwise stated. ${ }^{23}$

\section{Institutions}

The main conclusion from our empirical analysis is that institutional similarity is an important predictor of financial contagion during the emerging market crises of 1994, 1997, and 1998. With our two core priors, the joint probability of inclusion of the institutional similarity variables is at least $94 \%$ in all crises episodes with the exception of 1992. ${ }^{24}$ In 1992 the joint probability is above $80 \%$, which is high but not conclusive. For the emerging market crises of 1994, 1997 and 1998, credible intervals at 95\% for the

\footnotetext{
${ }^{22}$ Note that since we have a dummy variable among the regressors, namely Legal Origin, by taking the sample mean of variables we are evaluating the marginal effect at the average intercept. The marginal effect for the dummy variable Legal Origin is calculated as the change in probability when Legal Origin changes from 1 to 0 . The marginal effects for the finance variables (Fi1 and Fi2) take into account the consequent change in the interaction variable Fi1*Fi2.

${ }^{23}$ Results with the other two priors are available at http://fmg.lse.ac.uk/ amil/research.html.

${ }^{24}$ When the prior has $g=5 \bar{g}$, the joint probability of institutions in 1998 is still high but decreases to $90 \%$.
} 
marginal effects of institutional variables almost always exclude positive values, which is consistent with the wake-up call theory: countries that are institutionally similar to the ground zero country are more likely to experience crises. The only exceptions for these crises are the 95\% credible intervals for R. Law and Reg. Q. in 1998, which contain positive values. However, the effects of these two variables in 1998 are more likely to be zero, since their inclusion probabilities are only $27 \%$ and $20 \%$, respectively. ${ }^{25}$

Since it is difficult to interpret the size of the marginal effects of the institutional similarity variables, we now provide an alternative way of assessing whether the estimated effects are large or small. Consider a country $A$ that has average value for all regressors except for the institutional similarity variables (R. Law, Reg. Q. and Corrupt), all of which take value 0 : i.e. the country is identical to the ground zero country with respect to institutions. In addition, consider a country $B$ that also has average value for all regressors, but whose institutional variables take the same value as the country in our sample that is the most dissimilar, in terms of institutions, to the ground zero country ${ }^{26}$. Hence, countries $A$ and $B$ are different only with respect to institutions. Then, country $A$ is affected by the crisis in years 1994, 1997, 1998 with probabilities $(24 \%, 63 \%, 55 \%)$, whereas the corresponding probabilities for country $B$ are zero for each year. ${ }^{27}$ This confirms that institutional similarity played a particularly important role in the direction of spread of the emerging market crises of 1994, 1997 and 1998.

Our results on the effects of common legal origin are less emphatic. Zero values can never be confidently ruled out for the effect of Legal Or in any of the crises, especially in 1992, in which the effect of this variable seems to be negligible. The probability of inclusion of Legal Or. is highest in year 1997, in which positive values can be ruled out, indicating that countries with the same legal system as the ground zero country experienced lower probability of crisis. The 1997 ground zero country has British legal origin, which suggests that overall countries with British legal origin were ceteris

\footnotetext{
${ }^{25}$ Even for the EMU crisis of 1992, where institutional effects are clearly less important, the $95 \%$ credible interval for Reg. $Q$., the only variable with substantial inclusion probability, excludes positive values.

${ }^{26}$ The most dissimilar country in our sample is defined as the country that maximises the Euclidean distance with respect to the ground zero country. In terms of the variables that are defined in Section 3 and Table 1, it maximises $(R \text {. Law })^{2}+(\text { Reg. } Q)^{2}+(\text { Corrupt })^{2}$. According to our data, the most dissimilar countries to the ground zero countries (in terms of institutions) for 1992 (Finland), 1994 (Mexico), 1997 (Thailand) and 1998 (Russia) were Guinea-Bissau, Singapore, New Zealand and Singapore, respectively.

${ }^{27}$ For 1992 this probability decreases from $8 \%$ to zero.
} 
paribus less susceptible to financial crises, which is consistent with the results of the Law and Finance literature. ${ }^{28}$ The opposite effect is observed in years 1994 and 1998, where the ground zero countries have French and (Post-Socialist) civil law legal origins respectively. However, in these years the probability of the effect being zero is high.

We now turn to the other potential channels for financial contagion. Our results suggest that, after controlling for institutional similarity, other variables such as financial linkage, trade competition and distance have limited impact. We provide a detailed discussion in what follows.

\section{Finance}

The joint probability of inclusion of finance variables is above $90 \%$ only for the 1998 crisis, provided that the prior variance $g$ is equal to $\bar{g}$ or $2.46 \bar{g}$. This probability decreases to $84 \%$ when $g=5 \bar{g}$. Despite the high joint probability, the individual inclusion probabilities of $F i 1, F i 2$ and $F i 1^{*} F i 2$ are low. This is probably caused by multicollinearity. Despite of the problem of multicollinearity, it can be observed that the marginal effects of Fi1 and Fi2 in 1998 are positive, since credible intervals exclude negative values. Furthermore, the size of the mean marginal effects is non-negligible. Although the effect is not as clear for other years, the evidence for 1998 confirms the intuition that the more dependent the country is on the common lender, the more likely it is that it will be affected by the crisis.

\section{Trade and Distance}

The inclusion probability of Trade is highest in the 1997 crisis. It is $94 \%$ when $g=5 \bar{g}$, but it is below $90 \%$ when $g$ is equal to $\bar{g}$ or $2.46 \bar{g}$ (and it then takes values $81 \%$ and $87 \%$, respectively). However, $95 \%$ credible intervals indicate that the possibility of negative values can be confidently neglected, and that mean marginal effects are sizeable, indicating therefore that the trade channel of contagion was probably important in 1997. Although zero values are more likely in 1994 and 1998, 95\% credible intervals indicate that moderately large effects are still possible, and negative values are very unlikely.

\footnotetext{
${ }^{28}$ See Beck et al (2001)
} 
Therefore, Trade could also have been an important determinant in years 1994 and 1998. However, in contrast with Glick and Rose (1999), we find that Trade has a negligible effect in the 1992 crisis. It is Distance, instead, that seems to play an important role. Distance in 1992 is probably simply capturing the fact that EMU countries, which happen to be geographically near, were much more likely to be affected by the crisis. However, the negligible effect of trade is not caused by accounting for distance: if we excluded distance from the set of potential regressors the marginal effect of trade would continue to be small.

\section{Out of Sample Predictions}

We evaluate the predictive performance of the model using the prior with $g=\bar{g} 2.46$ and the following predictive rule, which is defined for $p=0.5,0.65,0.75,0.9,0.95$ :

$-y_{i}$ is predicted to be one when the posterior mean of $\operatorname{Pr}\left(y_{i}=1 \mid Z\right)>p$.

$-y_{i}$ is predicted to be zero when the posterior mean of $\operatorname{Pr}\left(y_{i}=1 \mid Z\right)<1-p$.

Predictions are made for $(1997,1998)$ based on parameter estimates from 1994 data. Similarly, predictions are made for $(1994,1998)$ based on parameters estimated with 1997 data, and for $(1994,1997)$ based on 1998 data. For each of these three cases we calculate two error rates: $E_{0}$ is the proportion of observations that were predicted to be zero but were actually 1 . Similarly, $E_{1}$ is the proportion of observations that were predicted to be one but were actually 0 . Tables 4 and 5 show the results.

Table 4 shows that there are very few countries for which the posterior probability of a crisis is high, and this introduces a small sample bias in our estimate of $E_{1}$. For example, if 1994 data is used to predict the 1997-98 crises, four cases have a posterior probability of a crisis greater than 0.90 . Three of these, Indonesia, the Republic of Korea and Malaysia in 1997 actually suffered a crisis. ${ }^{29}$ Given the small number of cases that are predicted to be 1 , the estimate of the error rate is bound to be imprecise.

Table 5 shows that $E_{0}$ is equal to 0 when $1-p$ is 0.05 , and it is smaller than 0.1 when $1-p$ is 0.1 . This suggests that the model produces reliable predictions of zeros, in

\footnotetext{
${ }^{29}$ A crisis is also (incorrectly) predicted for China in 1997.
} 
the sense that a small posterior mean of $\operatorname{Pr}\left(y_{i}=1 \mid Z\right)$ can be taken as strong evidence against the occurrence of a crisis.

\section{Conclusions}

We contribute to the empirical literature on financial contagion by considering institutional similarity to the ground-zero country, measured via governance indicators, as a determinant of the direction of spread of currency crises. We find that for the emerging market crises of 1994, 1997, and 1998, institutional similarity played a substantial role in determining the direction of contagion. Simultaneously, we consider more traditional channels of contagion, including trade and financial links. We are thus able to establish the relative importance of these various channels.

Our analysis also utilizes recent econometric methodology that is relevant to the analysis of financial contagion. In the absence of a single unified model of financial contagion, researchers are faced with model uncertainty in estimation and prediction. We use Bayesian model averaging to overcome these problems, a method hitherto unused in the literature on financial contagion.

Our results provide direction to theoretical modelers on the right mix of ingredients that should go into a potential unified model of financial contagion.

\section{Bibliography}

Akaike, H, (1978), “A new look at the Bayes Procedure," Biometrika, 65, 53-59.

Albert, J.H. and Chib, S. (1995), "Bayesian Analysis of Binary and Polychotomous Response Data," Journal of the American Statistical Association 88, 669-679.

Allen, F. and Gale, D. (2000), “Financial Contagion,” Journal of Political Economy, 108, 1-33

Basu R. (1998): Contagion Crises: The Investors' Logic, mimeograph UCLA Los Angeles

Beck, T., Demirgüç-Kunt, A. and Levine, R.E. (2001), "Legal Theories of Financial Development" Oxford Review of Economic Policy, 17, 483-501

Beck, T., and Levine, R.E. (2005), "Legal Institutions and Financial Development" in C. Menard and M. Shirley, (eds.), Handbook of New Institutional Economics, Kluwer Dordrecht (The Netherlands).

Berger, J. and Selke, T. (1987), "Testing of a point null hypothesis: the irreconcilability of significance levels and evidence (with discussion)," Journal of the American Statistical Association, 82, 112-139.

Bernardo, J.M. (1979), "Reference Posterior Distributions for Bayesian Inference" (with discussion), Journal of the Royal Statistical Society, B, 41, 113-147. 
Berndt, E.R. and Savin, N.E., (1977), "Conflict among criteria for testing hypotheses in the multivariate linear-regression model," Econometrica, 45, 1263-1277.

Box, G.E.P. and Tiao, G.C. (1992), Bayesian Inference in Statistical Analysis. Wiley (New York).

Caramazza, F., Luca, A. and Salgado, R. (2000), "Trade and Financial Contagion in Financial Crises," IMF Working Paper, WP/00/55.

Dasgupta, A. (2004), "Financial Contagion through Capital Connections: A Model of the Origin and Spread of Bank Panics," Journal of the European Economic Association, 2, 1049-1084.

Demirgüç-Kunt, A. and Detragiache, E. (1998), "Financial Liberalisation and Financial Fragility" in Annual World Bank Conference on Development Economics 1998, B. Plezkovic and J Stiglitz, (eds.), 30331.

Drazen, A. (1998), "Political Contagion in Currency Crises," mimeo, University of Maryland.

Dungey, M, Fry, R, González-Hermosillo, B. and Martin, V.L. (2003), "Empirical Modelling of Contagion: A Review of Methodologies," CERF working paper, \# 8, available at: http://rspas.anu.edu.au/economics/staff/dungey/pdfs/reviewdfgm.pdf

Dungey, M. and Tambakis, D. (2003), “International Financial Contagion: What do we know?" CERF Working Paper \# 9.

Eichengreen, B, Rose, A. and Wyplosz, C. (1996), "Contagious Currency Crises," NBER Working Paper \#5681.

Fernández, C, Ley, E. and Steel, M. (2001) “Benchmark priors for Bayesian model averaging,” Journal of Econometrics, 100, 381-427.

Geisser, S. (1984) "On prior distributions for binary trials (with discussion)" American Statistician, 38, 244-251.

Gerlach, S. and Smets, F. (1995): Contagious Speculative Attacks; European Journal of Political Economy, 11, 5-63.

Glick, R. and Rose, A. (1999), “Contagion and Trade: Why Are Currency Crises Regional?" Journal of International Money and Finance, 18, 603-617

Goldstein M. (1998): The Asian Financial Crisis; Institute for International Economics Washington DC

Goldstein, I. and Pauzner, A. (2004), "Contagion of Self-Fulfilling Currency Crises Due to the Diversification of Investment Portfolios," Journal of Economic Theory, 119, 159-183.

Greene, W.H. (2003), Econometric Analysis. $5^{\text {th }}$ Ed., Prentice Hall (New Jersey).

Hernandez, L. and Valdes, R. (2001), "What Drives Contagion: Trade, Neighbourhood or Financial Links?" IMF Working Paper WP 01/29.

Holmes, C.C. and Held, L. (2006), "Bayesian Auxiliary Variable Models for Binary and Multinomial Regression," Bayesian Analysis, 1, 145-168.

Jeffreys, J. (1961), Theory of Probability. Oxford University Press (Oxford).

Kaminsky, G., Lizondo, S. and Reinhart, C. (1998), "Leading Indicators of Currency Crises" IMF Staff papers, 45, 1-48.

Kaminsky, G. and Reinhart, C. (1999), "The Twin Crises: the Causes of Banking and Balance of Payments Problems," American Economic Review 89, 473-500.

Kaminsky, G. and Reinhart, C. (2000), “On Crises, Contagion and Confusion,” Journal of International Economics, 145-168.

Kaminsky, G. and Schmukler, S. (2003), "Short-Run Pain, Long Run Gain: The Effects of Financial Liberalisation" IMF Working Paper 2003 / 34. 
Kaufmann, D., Kraay, A. and Zoido-Lobaton, P. (1999), “Governance Matters,” World Bank Working Paper \# 2196

Koop, G. (2003) Bayesian Econometrics. Wiley (London).

La Porta, R., Lopez-de-Silanes, F., Shleifer, A. and Vishny, R. (1998), “Law and Finance,” Journal of Political Economy, 106, 1113 -1155.

Lee, P. (1987), Bayesian Statistics: An Introduction, $1^{\text {st }}$ ed., Oxford University Press (New York).

Porter, M.E. (1996), "Capital Choice: National Systems of Investment," in As If the Future Mattered: Translating Social and Economic Theory into Human Behavior, N.A. Goodwin (ed.), Ann Arbor: University of Michigan Press, 15-44.

Rigobon, R. (1998), "Informational Speculative Attacks: Good News is No News," MIT Working Paper

Selke, T., Bayarri, M.J. and Berger, J. (2001), "Calibration of P-values for testing precise null hypotheses," The American Statistician 55, 62-71.

Van Rijckeghem, C. and Weder, B.S. (2001). "Sources of Contagion; Finance or Trade?" Journal of International Economics, 45, 293-308.

Van Rijckeghem, C. and Weder, B.S. (2003). "Spillovers through banking centers: a panel data analysis of bank flows," Journal of International Money and Finance, 22, 483-509. 


\begin{tabular}{|l|l|}
\hline$Y$ & $\begin{array}{l}\text { Indicator of whether country } i \text { experienced a currency crisis; Glick and Rose (1999) and Van } \\
\text { Rijckeghem and Weder (2001) }\end{array}$ \\
\hline Trade & Trade competitiveness as defined in Glick and Rose (1999) \\
\hline Dom. Cred. & Growth of Domestic Credit \\
\hline Bud/GDP & Budget Position as a percentage of GDP \\
\hline CA/GDP & Current account position as a percentage of GDP \\
\hline Growth & Real rate of GDP per capita growth \\
\hline M2/Res & Ratio of M2 to central bank foreign reserves \\
\hline Inflation & Domestic CPI inflation \\
\hline GDP & GDP per capita at the beginning of the year measured in 1990 US \$ \\
\hline Distance & Great circle distance between capitals of country $i$ and ground zero country in km \\
\hline Legal Or. & Legal Origin Dummy: 1 if a country has the same legal system as the ground zero country \\
\hline R. Law & $\begin{array}{l}\text { Similarity, to ground zero country, in the degree to which the rule of law is upheld. Decreasing } \\
\text { with similarity. Original data from Kaufmann } \text { et al. (1999). }\end{array}$ \\
\hline Reg. $Q$. & $\begin{array}{l}\text { Similarity, to ground zero country, in Regulatory quality. Decreasing with similarity. Original data } \\
\text { from Kaufmann } \text { et al. (1999). }\end{array}$ \\
\hline Corrupt & $\begin{array}{l}\text { Similarity, to ground zero country, in Levels of Corruption. Decreasing with similarity. Original } \\
\text { data from Kaufmann } \text { et al. (1999). }\end{array}$ \\
\hline Fi1 & The proportion of a country's total borrowing that was borrowed from the common lender. \\
\hline Fi2 & A country's borrowing as a proportion of the total loans made by the common lender. \\
\hline Fi $*$ Fi2 & The product of Fi1 times Fi2. \\
\hline
\end{tabular}

Table 1: Definition of variables. 


\begin{tabular}{|c|c|c|c|c|c|c|c|c|}
\hline & \multicolumn{4}{|c|}{ Crises in 1992} & \multicolumn{4}{|c|}{ Crises in 1994} \\
\hline & \multirow[b]{2}{*}{$p$} & \multicolumn{3}{|c|}{$\begin{array}{l}\text { Mean and } 95 \% \text { credible interval for } \\
\text { marginal effects }\end{array}$} & \multirow[b]{2}{*}{$p$} & \multicolumn{3}{|c|}{$\begin{array}{l}\text { Mean and } 95 \% \text { credible interval } \\
\text { for marginal effects }\end{array}$} \\
\hline & & $\begin{array}{l}\text { Lower } \\
\text { limit }\end{array}$ & Mean & $\begin{array}{l}\text { Upper } \\
\text { limit }\end{array}$ & & $\begin{array}{l}\text { Lower } \\
\text { limit }\end{array}$ & Mean & $\begin{array}{l}\text { Upper } \\
\text { limit }\end{array}$ \\
\hline Trade & 0.29 & 0 & 0.013 & 0.089 & 0.62 & 0 & 0.090 & 0.491 \\
\hline $\begin{array}{l}\text { Dom. } \\
\text { Cred. }\end{array}$ & 0.34 & 0 & 6.0E-05 & 4.00E-04 & 0.24 & $-1.2 \mathrm{E}-04$ & $-1.1 E-05$ & 8.3E-05 \\
\hline $\mathrm{Bud} / G D P$ & 0.40 & -0.008 & -0.001 & 0 & 0.49 & 0 & 0.001 & 0.008 \\
\hline$C A / G D P$ & 0.33 & $-7.1 E-05$ & 3.3E-04 & 0.003 & 0.23 & $-1.7 E-04$ & 1.3E-04 & 8.3E-04 \\
\hline Growth & 0.26 & -0.003 & $-4.2 E-04$ & 0 & 0.23 & $-2.1 E-04$ & 1.0E-04 & 0.001 \\
\hline M2/Res & 0.24 & 0 & 8.5E-05 & 0.001 & 0.35 & $-5.1 E-04$ & -7.7E-05 & 3.1E-06 \\
\hline Inflation & 0.46 & -0.002 & $-3.2 E-04$ & 0 & 0.24 & $-2.5 E-05$ & 3.3E-05 & $2.2 \mathrm{E}-04$ \\
\hline$G D P$ & 0.21 & $-4.9 E-07$ & $-2.7 E-08$ & 3.7E-07 & 0.32 & $-5.2 E-06$ & $-6.4 \mathrm{E}-07$ & $3.9 \mathrm{E}-07$ \\
\hline Distance & 0.92 & $-3.9 E-05$ & $-1.1 E-05$ & 0 & 0.23 & $-1.7 E-07$ & 1.1E-07 & $1.4 \mathrm{E}-06$ \\
\hline Legal Or. & 0.12 & -0.001 & $-4.9 E-04$ & 0 & 0.56 & 0 & 0.013 & 0.173 \\
\hline R. Law & 0.28 & -0.049 & -0.002 & 0.033 & 0.55 & -0.049 & -0.009 & 0 \\
\hline Reg. $Q$. & 0.62 & -0.221 & -0.046 & 0 & 0.37 & -0.040 & -0.006 & 0 \\
\hline Corrupt & 0.24 & -0.042 & -0.002 & 0.025 & 0.47 & -0.038 & -0.006 & 0 \\
\hline$F i 1$ & - & 0 & - & - & 0.23 & -0.057 & -0.005 & 2.7E-02 \\
\hline$F i 2$ & - & 0 & - & - & 0.58 & 0 & 0.891 & 4.29 \\
\hline$F i 1 * F i 2$ & - & - & - & - & 0.28 & - & - & - \\
\hline Constant & 0.42 & - & - & - & 0.61 & - & - & - \\
\hline & $\begin{array}{l}\mathrm{P}(\text { Fina } \\
\mathrm{P}(\text { Instit }\end{array}$ & $\begin{array}{c}= \\
\text { ons })=0 .\end{array}$ & & & $\begin{array}{l}\mathrm{P}(\text { Fina } \\
\mathrm{P}(\text { Instit }\end{array}$ & $\begin{aligned} & =0.7 \\
\text { ons }) & =\mathbf{0} .\end{aligned}$ & & \\
\hline
\end{tabular}

Table 2: Probabilities of inclusion, posterior mean and credible intervals for the crises in 1992 and 1994. $p$ is the probability of inclusion of each variable. $\mathrm{P}$ (Finance) is the joint probability of inclusion of Fi1, Fi2 and Fi ${ }^{*}$ Fi2. $\mathrm{P}$ (Institutions) is the joint probability of inclusion of R. Law, Reg. Q. and Corrupt. Prior with $g=\bar{g} 2.46$ 


\begin{tabular}{|c|c|c|c|c|c|c|c|c|}
\hline & \multicolumn{4}{|c|}{ Crises in 1997} & \multicolumn{4}{|c|}{ Crises in 1998} \\
\hline & \multirow{2}{*}{$P$} & \multicolumn{3}{|c|}{$\begin{array}{l}\text { Mean and } 95 \% \text { credible interval for } \\
\text { marginal effects }\end{array}$} & \multirow{2}{*}{$P$} & \multicolumn{3}{|c|}{$\begin{array}{l}\text { Mean and } 95 \% \text { credible interval } \\
\text { for marginal effects }\end{array}$} \\
\hline & & $\begin{array}{l}\text { Lower } \\
\text { limit }\end{array}$ & $\begin{array}{l}\text { Pos. } \\
\text { Mean } \\
\end{array}$ & $\begin{array}{l}\text { Upper } \\
\text { limit } \\
\end{array}$ & & $\begin{array}{l}\text { Lower } \\
\text { limit }\end{array}$ & $\begin{array}{l}\text { Pos. } \\
\text { Mean } \\
\end{array}$ & \begin{tabular}{|l|} 
Upper \\
limit \\
\end{tabular} \\
\hline Trade & 0.87 & 0 & 0.484 & 1.25 & 0.27 & -0.101 & 0.127 & 1.02 \\
\hline $\begin{array}{l}\text { Dom. } \\
\text { Cred. }\end{array}$ & 0.40 & -0.006 & $-1.1 E-03$ & 0 & 0.13 & -0.004 & $-2.4 \mathrm{E}-04$ & 0.001 \\
\hline $\mathrm{Bud} / G D P$ & 0.64 & 0 & 0.012 & 0.044 & 0.18 & 0 & 0.003 & 0.027 \\
\hline$C A / G D P$ & 0.38 & -0.013 & -0.002 & 0 & 0.17 & 0 & 0.002 & 0.015 \\
\hline Growth & 0.34 & -0.019 & $-2.2 E-03$ & 0.002 & 0.18 & 0 & 0.004 & 0.036 \\
\hline M2/Res & 0.95 & 0 & 0.011 & 3.0E-02 & 0.24 & 0 & 0.005 & 0.032 \\
\hline Inflation & 0.22 & $-1.1 E-03$ & 1.1E-05 & 0.001 & 0.14 & -0.002 & 2.8E-04 & 0.004 \\
\hline$G D P$ & 0.24 & $-1.1 E-05$ & $-1.1 E-06$ & 1.1E-06 & 0.20 & $-3.5 E-06$ & 3.1E-06 & $3.5 \mathrm{E}-05$ \\
\hline Distance & 0.24 & $-9.6 E-06$ & $-8.6 \mathrm{E}-07$ & $1.8 \mathrm{E}-06$ & 0.29 & 0 & 7.8E-06 & 5.1E-05 \\
\hline Legal Or. & 0.74 & -0.324 & $-1.3 E-01$ & 0 & 0.34 & 0 & 0.159 & 0.838 \\
\hline R. Law & 0.83 & -0.230 & -0.081 & 0 & 0.27 & -0.213 & 0.021 & 0.358 \\
\hline Reg. $Q$. & 0.43 & -0.285 & -0.055 & 0 & 0.20 & -0.020 & 0.020 & 0.212 \\
\hline Corrupt & 0.21 & -0.023 & -0.002 & 8.0E-04 & 0.82 & -0.681 & -0.289 & 0 \\
\hline Fil & 0.22 & -0.184 & 0.098 & 1.11 & 0.17 & 0 & 0.433 & 1.22 \\
\hline $\mathrm{Fi} 2$ & 0.21 & -0.948 & 0.122 & 1.72 & 0.35 & 0 & 6.53 & 12.33 \\
\hline$F i 1 * F i 2$ & 0.21 & - & - & - & 0.59 & - & - & - \\
\hline Constant & 0.44 & - & - & - & 0.49 & - & - & - \\
\hline & $\begin{array}{l}\mathrm{P}(\text { Final } \\
\mathrm{P}(\text { Instit }\end{array}$ & $\begin{aligned} & =0 . \\
\text { ons }) & =\mathbf{0} .\end{aligned}$ & & & $\begin{array}{l}\mathrm{P}(\text { Fina } \\
\mathrm{P}(\text { Insti }\end{array}$ & $\begin{aligned} & =\mathbf{0 .} \\
\text { ons }) & =\mathbf{0 .}\end{aligned}$ & & \\
\hline
\end{tabular}

Table 3: Probabilities of inclusion, posterior mean and credible intervals for the crises in 1997 and 1998. $p$ is the probability of inclusion of each variable. $\mathrm{P}$ (Finance) is the joint probability of inclusion of Fi1, Fi2 and Fi ${ }^{*} F i 2$. $\mathrm{P}$ (Institutions) is the joint probability of inclusion of R. Law, Reg. Q. and Corrupt. Prior with $g=\bar{g} 2.46$ 


\begin{tabular}{|c|c|c|c|c|c|c|}
\hline & $p$ & 0.5 & 0.65 & 0.75 & 0.90 & 0.95 \\
\hline \multirow[t]{3}{*}{1994} & $E_{1}$ & 0.56 & 0.38 & 0.30 & 0.25 & 0.00 \\
\hline & $N P$ & 39 & 16 & 10 & 4 & 1 \\
\hline & $A N$ & 27 & 27 & 27 & 27 & 27 \\
\hline \multirow[t]{3}{*}{1997} & $E_{1}$ & 0.71 & 0.69 & 0.68 & 0.67 & 0.00 \\
\hline & $N P$ & 45 & 36 & 22 & 6 & 1 \\
\hline & $A N$ & 23 & 23 & 23 & 23 & 23 \\
\hline \multirow[t]{3}{*}{1998} & $E_{1}$ & 0.56 & 0.29 & 0.20 & n.a. & n.a. \\
\hline & $N P$ & 16 & 7 & 5 & 0 & 0 \\
\hline & $A N$ & 18 & 18 & 18 & 18 & 18 \\
\hline
\end{tabular}

Table 4: Out of Sample Predictions of 1. $y_{i}$ is predicted to be one when the posterior mean of $\operatorname{Pr}\left(y_{i}=1 \mid Z\right)>$ $p$. When the models are estimated with 1994 data, predictions are made for $(1997,1998)$. Similarly, predictions are made for $(1994,1998)$ based on 1997 data, and for $(1994,1997)$ based on 1998 data. $N P$ is the number of observations predicted to be $1 . E_{1}$ is the proportion of $N P$ that was actually $0 . A N$ is the actual number of ones in the validation sample.

\begin{tabular}{|c|c|c|c|c|c|c|}
\hline & $1-p$ & 0.5 & 0.35 & 0.25 & 0.1 & 0.05 \\
\hline \multirow{3}{*}{1994} & $E_{0}$ & 0.15 & 0.09 & 0.09 & 0.04 & 0.00 \\
\hline & NP & 68 & 54 & 45 & 25 & 12 \\
\hline & AN & 80 & 80 & 80 & 80 & 80 \\
\hline \multirow[t]{3}{*}{1997} & $E_{0}$ & 0.15 & 0.14 & 0.12 & 0.06 & 0.00 \\
\hline & NP & 67 & 59 & 52 & 34 & 17 \\
\hline & AN & 89 & 89 & 89 & 89 & 89 \\
\hline \multirow[t]{3}{*}{1998} & $E_{0}$ & 0.12 & 0.08 & 0.06 & 0.09 & 0.00 \\
\hline & NP & 89 & 75 & 54 & 32 & 10 \\
\hline & AN & 87 & 87 & 87 & 87 & 87 \\
\hline
\end{tabular}

Table 5: Out of Sample Predictions of 0. $y_{i}$ is predicted to be zero when the posterior mean of $\operatorname{Pr}\left(y_{i}=1 \mid Z\right)<$ 1-p. When the models are estimated with 1994 data, predictions are made for $(1997,1998)$. Similarly, predictions are made for $(1994,1998)$ based on 1997 data, and for $(1994,1997)$ based on 1998 data. $N P$ is the number of observations predicted to be $0 . E_{0}$ is the proportion of $N P$ that was actually $1 . A N$ is the actual number of zeros in the validation sample. 
Appendix A: Details of Bayesian Methodology

\section{A.1: Prior Elicitation for the parameter $g$.}

We comment first on why we do not simply choose a very large value for $g$. It is easy to see that choosing very high values for $g$ (which results in a very high prior variance) results in priors that put all probability weight on $y=0$ or $y=1$. For example, suppose that there is only one regressor in the model and no constant term. A sufficiently large prior variance for the slope coefficient implies that the probability that $\mathrm{Z} \theta$ is in the interval $(-4,4)$ is approximately zero. Note that in order to predict the outcome of $y_{\mathrm{i}}$ it does not matter in practice if $Z \theta$ is -5 or -250 , since both values result in the probability of $y_{\mathrm{i}}=1$ being approximately equal to zero. Therefore, since a large prior variance effectively rules out that $\mathrm{Z} \theta$ lies in $(-4,4)$, the size of the slope coefficient is no longer relevant, and all we would need, should the prior information be true, in order to predict perfectly the outcome of $y_{\mathrm{i}}$, is the sign of the slope coefficient. Thus, because the prior would be so informative, the only relevant information that we would expect from the data would concern the sign of the slope coefficient. A large amount of data would be necessary to change such strong prior beliefs on large probabilities and small marginal effects.

We comment next on the three values of $g$ that we actually choose. Our first choice of prior fixes a value of $g$ such that:

$$
\operatorname{Var}\left(\bar{z}_{j}^{\prime} \theta_{j}\right)=\bar{z}_{j} V_{j} \bar{z}_{j}^{\prime}=1
$$

where $\bar{z}_{j}$ is a $k_{j} \times 1$ vector containing the average sample values of $Z_{j}$. This implies the following value of $g$ :

$$
\bar{g}=\left(\bar{z}_{j}^{\prime}\left(Z_{j}^{\prime} Z_{j}\right)^{-1} \bar{z}_{j}\right)^{-1}
$$

To see why this choice is appealing, recall that $\bar{\pi}=\operatorname{Pr}\left(y=1 \mid \bar{z}_{j}, \theta_{j}, M_{j}\right)=\Phi\left(\bar{z}_{j}^{\prime} \theta_{j}\right)$, where $\Phi$ is the distribution function of a standard normal and therefore $\bar{\pi}$ is the probability of $(y=1)$ for a country with average values for the regressors. If we fix $g$ to be equal to $\bar{g}$, then our prior for $\bar{\pi}$ is a uniform in the interval $(0,1) .{ }^{3031}$

\footnotetext{
${ }^{30}$ To see why, note that using the second fundamental theorem of calculus, the Jacobian from $\bar{\pi}$ to $\widetilde{z}=\bar{z}_{j}^{\prime} \theta_{j}$ is the density function of a standard normal evaluated at $\widetilde{z}$.

${ }^{31}$ In addition, we note that if $Z$ contains an intercept term, then expression (2) is equal to $n$. A value of $g$ equal to $n$ has been recommended in the context of model selection in linear models by Fernandez, Ley and Steel (2001).
} 
Another popular choice of non-informative prior to estimate a probability is a $\operatorname{Beta}(1 / 2,1 / 2)$. In the context of a binomial likelihood, this prior is uninformative according to alternative criteria used by different authors (Jeffreys, 1961, Box and Tiao, 1973, Akaike, 1978 and Bernardo, 1979). Compared to the uniform prior, the Beta prior gives slightly more weight to values near to zero and near to 1 . In our model, this implies that values of $\theta_{j}$ that were further away from zero would receive greater prior weight. Within our framework, we can achieve this greater weight by choosing $g=a \bar{g}$, with $a>1$. After experimenting with several values for $a$, we found that $a=2.46$ results in a prior for $\bar{\pi}$ that approximates well to a Beta $(1 / 2,1 / 2)$. This is illustrated in Figure 1, which shows that our prior for $\bar{\pi}$ when $a=2.46$ is virtually undistinguishable from the Beta prior. Therefore, the second prior that we consider results from fixing $g=2.46 \bar{g}$. Finally, for sensitivity analysis we also consider prior (1) with $g=5 \bar{g}$.
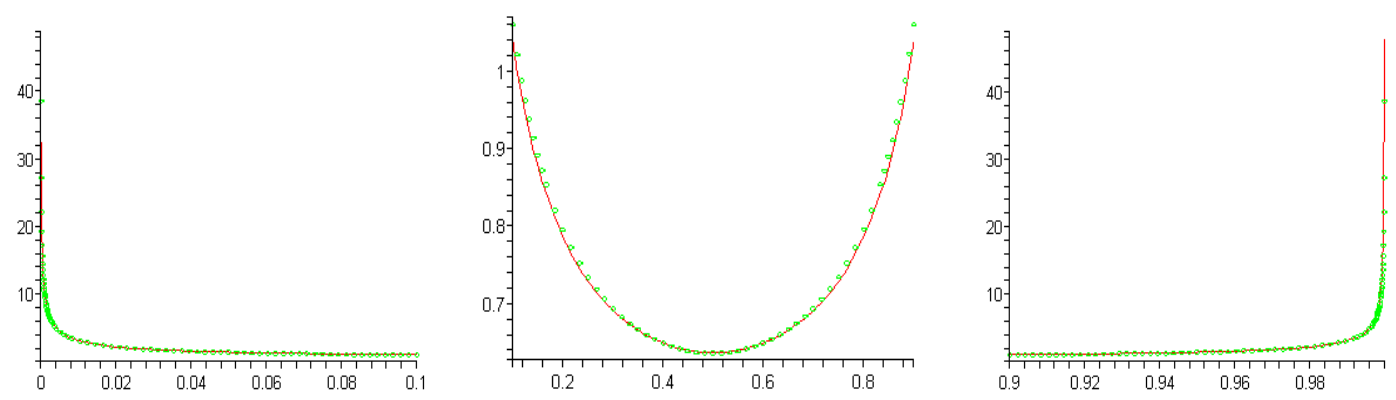

Figure 1: Three views of our prior density for $\bar{\pi}$ with $g=2.46 \bar{g}$ (continuous line) and a $\operatorname{Beta}(1 / 2,1 / 2)$ (dotted line).

\section{A.2: Computation.}

Let $M_{n}$ be the model visited in the $n^{\text {th }}$ iteration of the Markov Chain algorithm, let $\theta_{n}$ be the value of the non-zero parameters in $M_{n}$ at the $n^{\text {th }}$ iteration and similarly let $Y_{n}^{*}$ be the value of $Y^{*}$. Assuming prior (1) for the parameters in a model, and assuming that all possible models have equal prior probabilities, the iteration $(n+1)$ proceeds as follows:

1) Choose a model $M^{*}$ from a uniform distribution defined on the following set of models:

- Model $M_{n}$

- Models that result from dropping one regressor in $M_{n}$

- Models that result from adding one regressor to $M_{n}$ 
2) Set $M_{n+1}$ equal to $M^{*}$ with probability:

$$
\alpha=\min \left\{1, \frac{(1+g)^{-k * / 2} \exp \left(-1 / 2\left(Y_{n}^{*}\right)\left(I_{n}-1 /(1+g) Z_{*} V_{*} Z_{*}^{\prime}\right) Y_{n}^{*}\right)}{(1+g)^{-k_{n} / 2} \exp \left(-1 / 2\left(Y_{n}^{*}\right)\left(I_{n}-1 /(1+g) Z_{n} V_{n} Z_{n}^{\prime}\right) Y_{n}^{*}\right)}\right\}
$$

where $I_{n}$ is the identity matrix of dimension $n, Z_{*}$ is a $n \times k *$ matrix with the set of regressors contained in $M^{*}, k_{n}$ is the number of regressors in $M_{n}$ and $V_{*}$ and $V_{n}$ are defined as in (1). Set $M_{n+1}$ equal to $M_{n}$ with probability $1-\alpha$.

3) Draw $\theta_{n+1}$ from a normal density with covariance matrix $(\widetilde{V})$ and mean $(\tilde{\mu})$ equal to:

$$
\widetilde{V}=\frac{g}{g+1}\left(Z_{n+1}^{\prime} Z_{n+1}\right)^{-1} \quad \tilde{\mu}=\tilde{V} Z_{n+1}^{\prime} Y_{n}^{*}
$$

where $Z_{n+1}$ is the set of regressors that are included in model $M_{n+1}$.

4) Draw each of the components of $Y_{n+1}^{*}$ from univariate truncated normal distributions as explained in Albert and Chib (1995).

We calculate the posterior probability of model $M_{j}$ as the proportion of iterations that visit model $M_{j}$. Similarly, posterior means and credible intervals for $\theta$ or functions of $\theta$ (e.g. marginal effects) can be calculated using the draws obtained with the algorithm. 